\title{
UK astronomers hit out at funding council
}

[LONDON] Britain's astronomers are losing confidence in the Particle Physics and Astronomy Research Council (PPARC), according to a survey of members of the Royal Astronomical Society. Their main concern is the council's perceived failure to protect the existing ground-based astronomy programme from a $£ 7$-million (US\$10.5-million) funding cut that could lead to the closure of up to three telescopes to which Britain is a major contributor.

The savings are designed to help support the UK contribution towards the new Gemini project, two 'next-generation' eightmetre telescopes being planned jointly with the United States, Canada and countries of South America.

Summarizing the survey's findings at the start of the UK National Astronomy Meeting in Southampton last week, Malcolm Longair, president of the society and formerly Astronomer Royal for Scotland, said there was a feeling that PPARC could have managed the issue more effectively.

"There is considerable concern that PPARC has allowed the current crisis facing the ground-based astronomy programme to come about so suddenly so far as the wider community is concerned," said Longair.

But Ken Pounds, chief executive of PPARC and professor of astronomy at the University of Leicester, says that a succession of "funding squeezes" has left PPARC with little choice but to withdraw funding from two telescopes on La Palma, in the Canary Islands, as well as the UK-Schmidt Telescope in Australia. "We are going to have to make reductions to the size of the existing programme, for if we don't invest in new things, we will get left behind."

In January, a PPARC committee recommended that most of the $\mathfrak{E} 7$-million savings should come from the

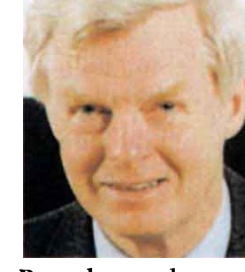

Pounds: cuts leave little choice. Isaac Newton Group of telescopes that are part of the Royal Observatory network but situated on La Palma.

Longair says there is "broad agreement" on the need to reduce Britain's existing groundbased astronomy programme to operate the new Gemini telescopes. But he says there remains "a strong expression of feeling that the current drastic round of economies being required is extremely damaging". $\mathrm{He}$ also says the lack of effective communication between PPARC and the astronomy community meant that many astronomers did not understand why the cuts had to be made.

Steve Unger, director at the La Palma site, is among those who believe that PPARC's latest proposals are unfair and shortsighted. Unger says that he was already implementing a 20 per cent "efficiency saving" following an earlier attempt at finding ways of diverting money into Gemini, a review panel that was chaired by James Hough, head of the department of physical sciences at the University of Hertfordshire.

Unger says he is now being asked to find an additional 15 per cent, which would effectively cripple a facility that in recent years has produced more highly cited papers than its Royal Observatory stablemates. He also believes that PPARC's plans to close one of the La Palma telescopes - the Jacobus Kapteym Telescope - will be largely symbolic, as the "cost of operating the telescope is very much less than the cost of demolishing it".

Astronomers trace part of PPARC's difficulties to a shift in government emphasis from 'big physics' projects towards the life sciences. "There is no question," says one senior astronomer, "that funding for physics and astronomy has fallen by two to three per cent per year over the past 10 to 15 years."

PPARC's problems, he says, can also be attributed to the 1993 White Paper on science and technology, which led to the break-up of the old Science and Engineering Research Council (SERC), and the emergence of PPARC and a separate council for engineering and physical sciences.

"Before the White Paper, when funding was tight, astronomy and particle physics could look elsewhere within the old SERC for money that had not been spent. This is now impossible, and astronomy has no equivalent of the Wellcome Trust." EnsanMasood

\section{Copyright treaties threaten information flow, says NRC}

[WASHINGTON] A committee of the US National Research Council (NRC) - the executive arm of the National Academy of Sciences - last week repeated its warning that international treaties now under consideration to govern copyright law for electronic databases could hamper the free flow of scientific information.

"The scientific community and its defenders must step in quickly to insist on further, open debate before these changes reach implementation," says the final report of the NRC Committee on Issues in the Transborder Flow of Scientific Data.

The committee, chaired by Stephen Berry, a professor of chemistry at the University of Chicago, began studying data policy issues in 1995. Last year it took the unusual step of releasing one chapter of its report early, immediately before a diplomatic conference on copyright treaty held by the World Intellectual Property Organisation (WIPO) in December. Several scientific organizations have argued that giving copyright to compilers of electronic databases would lead to researchers being charged for data they at present receive free (see Nature 384, 299; 1996).

WIPO representatives and others say these fears are overblown. But opposition was strong enough before the December conference for discussion of electronic databases to be dropped. The subject will be taken up again at an "information meeting" to be held by WIPO in September.

The NRC report released last week repeats the call for any new treaty to include "fair use" exceptions that would allow scientists and educators to use copyrighted databases either free or at reduced cost. The committee argues that the free and open exchange of scientific information is a "public good" that needs to be protected.

With this guiding principle in mind, government science agencies eager to cut their operating costs should be careful about privatizing the distribution of research data, says the committee. Those who contribute to a database - the scientific community should be able to use it free.

If a commercial distributor adds value to the raw data, the price for researchers and educators "should be no higher than the marginal cost of adding value". For their part, "all scientists conducting publicly funded research should make their data available immediately, or following a reasonable period for proprietary use".

When deciding whether to privatize a database, whether it contains Earth satellite imagery or information on the human genome, government agencies should consider such factors as how large and diverse the user community is, and whether the market can sustain more than one data provider. If there is no market beyond scientists, says the NRC committee, it makes sense for the government to continue to distribute the data.

The committee recognizes that some of the current conflict over copyright law stems from different use of the Internet businesses tend to protect information, but scientists want it exchanged openly. One possible solution would be for scientists to create their own international science network along the lines of the Internet II now being developed. Tony Reichhardt 